\title{
Entre a fauna e o design: um comparativo entre os animais e suas representações gráficas em rótulos de cachaça de meados do século $\mathrm{XX}$
} Between the fauna and the design: a comparison between animals and their graphic representations on cachaça labels from the mid-twentieth century

\author{
Swanne Almeida \& Solange Coutinho
}

representações gráficas, animais, fauna, rótulos de cachaça, cromolitografia

\begin{abstract}
Este artigo apresenta um comparativo entre as representações de animais em rótulos de cachaça e suas correspondências na fauna. O estudo trata-se de um recorte da pesquisa realizada por Almeida (2018), que investigou a recorrência de animais nos rótulos de cachaça brasileiros de meados do século XX. Os artefatos analisados fazem parte da Coleção Almirante (Fundaj, Recife-PE), composta majoritariamente por rótulos de cachaça entre as décadas de 1940 e 1950, com temáticas diversas, tais como: mulheres, homens, folclore, índios, paisagens, objetos, entre outras. Dentre estas temáticas, destaca-se o grupo de animais, a partir do qual a investigação do presente artigo se delineia, concentrando-se em caracterizar as referências faunísticas utilizadas e comparar o nível de semelhança e detalhamento entre o objeto real (animal) e sua representação gráfica (ilustração). Para análise da representação, utiliza-se como base, os ingredientes de estilo da ilustração proposto por Aswhin (1979). A partir das apreciações, observou-se uma tendência para representações gráficas naturalistas e com alto grau de detalhamento dos animais, revelando conhecimento das espécies por parte dos artistas gráficos e do público consumidor da época.
\end{abstract}

graphic representations, animals, fauna, cachaça labels, chromolithography

This article presents a comparison between the representations of animals on cachaça labels and their corresponding images in the fauna. The study is part of a research conducted by Almeida (2018), which investigated the recurrence of animals on Brazilian cachaça labels from the mid-twentieth century. The artifacts analyzed are part of the Almirante Collection (Fundaj, Recife-PE), composed mainly of cachaça labels from between the 1940s and 1950s, with various themes such as: women, men, folklore, Indigenous peoples, landscapes, objects, amongst others. Outstanding amongst these themes is the group of animals, on which the investigation of the present article is focused, concentrating on characterizing the faunal references used and comparing the level of similarity and detail between the real (animal) object and its graphical representation (illustration). The representational analysis was based on the ingredients of style exposed by Aswhin (1979). From the evaluations, a tendency was observed for naturalist graphic representations and which included a high degree of detail of the actual animals, thereby revealing knowledge of the species on the part of the graphic artists and the consuming public of the time.

\section{Introdução}

No final do século XVIII, a descoberta da litografia por Senefelder abriu novos horizontes para os impressos, que além de letras desenhadas, ganharam também ilustrações (Humbert, 1972). No caso do Brasil, os primeiros artefatos produzidos para os produtos nativos refletiam os motivos iconográficos europeus que já circulavam no mercado por meio da rotulagem dos produtos importados (Melo \& Ramos, 2011). Em Humbert (1972), publicação dedicada inteiramente a rótulos, apresenta-se exemplares da rotulagem desde o século XVII até o século $\mathrm{XX}$ provindos de diferentes países. Este autor relaciona o visual dos rótulos ao gosto, estilo, produção gráfica e às exigências de mercado características de cada período.

Dentro deste contexto, ao observar rótulos de cachaça brasileiros de meados do século XX, percebe-se uma predileção por certos temas. O repertório permeia referências à própria bebida, tais como elementos pictóricos de cana-de-açúcar, engenhos, taças, barris, garrafas; figuras humanas, seja na representação e erotização da figura feminina, seja na figura masculina em atividades boemias ou relativas à vida rural, ou ainda casais unidos no lazer e

Anais do 9 CIDI e 9 CONGIC

Luciane Maria Fadel, Carla Spinillo, Anderson Horta, Cristina Portugal (orgs.)

Sociedade Brasileira de Design da Informação - SBDI

Belo Horizonte | Brasil | 2019

ISBN 978-85-212-1728-2
Proceedings of the 9th CIDI and 9th CONGIC

Luciane Maria Fadel, Carla Spinillo, Anderson Horta, Cristina Portugal (orgs.)

Sociedade Brasileira de Design da Informação - SBDI Belo Horizonte | Brazil | 2019

ISBN 978-85-212-1728-2 
grupos em festejos; temas referentes a entretenimento e cultura, tais como jogos de cartas, personagens, esportes e religião; referências ao período, como rótulos que retratam algum acontecimento ou situação histórica da época, veículos de transporte como o trem, o caminhão ou mesmo o avião; e os animais mais variados possíveis, não se restringindo àqueles ligados à produção da aguardente.

Conforme Almeida (2018), os animais tornaram-se uma temática presente nas amostras dos estabelecimentos litográficos brasileiros já no final do século XIX, ocorrência observada graças ao registro de marcas nos livros das juntas comerciais. No contexto aguardenteiro, esta presença temática atrai o olhar investigativo devido a sua alta incidência nas produções da primeira metade do século XX e à especificidade da fauna apresentada, seja na escolha dos animais ou mesmo nas representações gráficas dos mesmos. As escolhas não se restringem a animais tradicionais e comuns na heráldica, como águias e leões. Pelo contrário, os nomes apresentados são dotados de regionalismos e espécies nativas, tais como "suçuarana" e "aratanha".

Estas ocorrências foram analisadas por Almeida (2018), no intuito de contextualizar e investigar os fatores que desencadearam e potencializaram esta escolha temática na rotulagem aguardenteira do período mencionado. Para tal estudo, a autora utilizou a Coleção Almirante de rótulos de cachaça, propriedade da Fundação Joaquim Nabuco (Recife-PE). Esta coleção é formada por mais de 4600 rótulos de cachaça divididos entres dezoito estados brasileiros ${ }^{1}$. A quantidade de cada estado é variável, todavia São Paulo, Rio de Janeiro e Minas Gerais são aqueles que possuem a maior quantidade de exemplares, representando juntos mais da metade do acervo. Os exemplares são em sua maioria rótulos de cachaça das décadas de 1940 e 1950.

Neste artigo, expõe-se um recorte do trabalho de Almeida (2018), no que tangencia o teor das representações gráficas de animais presentes nos rótulos da Coleção Almirante, com o intuito de comparar o nível de semelhança e detalhamento entre o objeto real (animal) e sua representação gráfica (ilustração). Com tal propósito, a investigação se conduz em três etapas principais: (1) Categorização dos animais; (2) Identificação de espécies nativas e estrangeiras; e, (3) Comparativo entre as representações gráficas e os animais. Para este último, utiliza-se ingredientes do estilo de ilustrações apontados por Ashwin (1979), que propõe uma investigação por meio do emprego de sete variáveis semânticas e sintáticas. Nesta análise foram incluídas apenas as variáveis mais relevantes para avaliação da semelhança entre o animal representado e sua espécie na natureza.

Espera-se com esta proposta, colaborar para caracterização da produção da época, compreendendo as referências faunísticas utilizadas e as diferentes formas de representação gráfica. A seguir apresentamos a categorização dos animais proposta para os rótulos da Coleção Almirante que trazem animais como tema principal.

\section{Categorização dos Animais}

O Brasil é um país reconhecido por ter uma grande biodiversidade. De acordo com o Catálogo Taxonômico da fauna brasileira, até o momento são conhecidas 116.087 espécies de animais. A busca pelo entendimento da fauna brasileira, bem como de uma classificação básica dos animais foi necessária para caracterizar os achados na coleção e efetuar posteriormente a devida comparação com as referências faunísticas. Desta forma, a pesquisa voltou-se inicialmente à zoologia, com a finalidade de descobrir como agrupar os animais de acordo com seus aspectos biológicos e formais.

A bibliografia de classificação e taxonomia de animais é bastante extensa e específica. Dentre os sistemas de classificação, temos o de Carl Von Linné (1707-1778) exposto por Lopes (2004). Neste sistema, os agrupamentos partem da unidade básica que é a espécie. Conforme esta classificação, os filos existentes na coleção são: cordados (aparecem peixes, aves, répteis

\footnotetext{
1 Os estados que compõem a Coleção Almirante são: Alagoas, Bahia, Ceará, Espírito Santo, Goiás, Maranhão, Mato Grosso, Minas Gerais, Pará, Paraíba, Paraná, Pernambuco, Piauí, Rio de Janeiro, Rio Grande do Norte, Rio Grande do Sul, Santa Catarina, São Paulo e Sergipe.
} 
e mamíferos), artrópodes (aparecem crustáceos, insetos) e moluscos (apenas um caracol). Para agrupar os animais segundo esta classificação, os grupos seriam compostos pelos vertebrados: mamíferos, répteis, peixes, aves e anfíbios; e pelos invertebrados: crustáceos, insetos e moluscos.

Contudo, observou-se que ao utilizar a rigor a taxonomia biológica, a classificação tornavase muito complexa e descontextualizada do fim, que seria representar o repertório utilizado nos rótulos de cachaça, refletindo mais sinteticamente o conteúdo das marcas. Por exemplo, formalmente nas aves encontramos: falconiformes (águias), passeriformes (passarinhos como o curió), psitaciformes (papagaios e araras), galliformes (galos e galinhas), entre outras ordens. À medida que se divide os animais desta forma, a nomenclatura fica cada vez mais intricada, perdendo o sentido para os objetivos propostos. Em função disso, foi decidido utilizar a taxonomia formal como apoio, entretanto adotar terminologias mais populares paras as categorias, relacionando a estas, o ambiente ao qual os animais estavam ligados, para desta forma transmitir o conteúdo almejado. Almeida (2018) encontrou 402 exemplares na Coleção Almirante que apresentavam animais ilustrados, os quais foram divididos da seguinte forma:

- Mamíferos domésticos: Os cães e gatos presentes na coleção. Apesar de cavalos serem considerados, de certa forma, domésticos, neste grupo entraram apenas os cachorros e gatos, que são mamíferos conhecidamente como domésticos e que à princípio são descontextualizados do meio rural.

- Rurais: Todos os animais que podem ser contextualizados mais diretamente no ambiente rural. Desde aves, como patos, galos e galinhas a mamíferos utilizados para transporte ou comuns nas criações, como bois, cavalos, coelho, carneiro e bode.

- Aves: Todos os tipos de ave, exceto aquelas que foram enquadradas no grupo rural. Neste grupo se destacam as águias como predominantes, seguidas pelos passarinhos.

- Insetos: Os invertebrados que já se incluem neste grupo tradicionalmente.

- Répteis: Os répteis da coleção, que abarcam tartarugas, serpentes, lagartos e jacarés.

- Mamíferos Selvagens: Todos os mamíferos que no Brasil não são tradicionalmente domesticados nem são utilizados no ambiente rural. Alguns exemplos são: leão, onça, girafa, macacos e tatu.

- Roedores: Como são mamíferos de porte menor e bem específicos, foram dispostos separadamente do grupo anterior. Alguns exemplos são: rato, preá e capivara.

- Peixes e Mamíferos aquáticos: Todos os peixes encontrados, sem distinção. Alguns exemplos são: Surubim e Cavalo Marinho. Adicionamos também neste grupo, o único mamífero aquático encontrado: a "Toninha".

- Moluscos: O único molusco encontrado: um caracol.

- Crustáceos: Lagostas, camarões, caranguejos e outros.

- Mitológicos: Aqui foram enquadradas as criaturas mitológicas: os dragões e a fênix encontrada.

A partir desta classificação, os animais encontrados na coleção foram categorizados. $\mathrm{Na}$ figura 1, observa-se que a predominância é do grupo de aves, com destaque para as águias, com 26 exemplares. Em segundo lugar, estão os animais da vida rural, com destaque para o galo, com 33 exemplares, seguido pelo cavalo, presente em 23 exemplares. Em terceiro lugar de incidência, encontra-se o grupo dos mamíferos selvagens, sendo o leão, o animal de maior constância. 


\section{ANIMAIS NA ALMIRANTE}

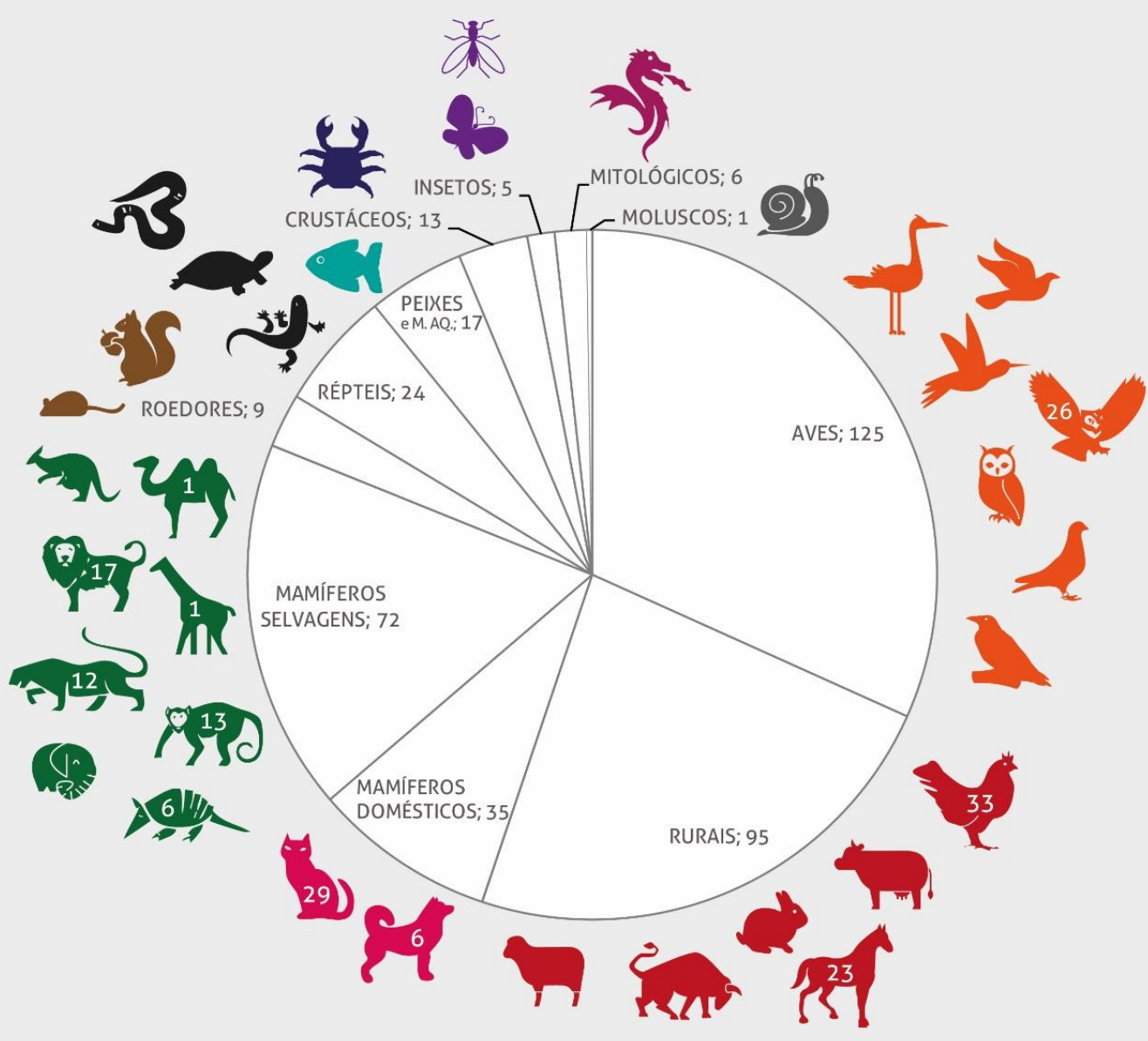

Nos mamíferos selvagens, temos tanto os animais nativos brasileiros, como também as espécies exóticas, como o já mencionado leão, a girafa, o camelo, todos trazidos ao Brasil. Em quarto lugar temos os animais domésticos, com uma grande predominância de gatos. É importante notar que alguns dos gatos que aparecem nessa categoria fazem parte de um grupo de rótulos de estoque ${ }^{2}$ que parece ter sido muito popular na época. Os outros grupos têm menor incidência: répteis (24), peixes e mamíferos aquáticos (17), crustáceos (13), roedores (9), mitológicos (6), insetos (5) e moluscos (1). O galo, o gato, a águia e o leão, respectivamente, são os animais que mais se destacam nos quantitativos, provavelmente por influência da heráldica, já que foram animais que compuseram brasões por séculos. $\mathrm{Na}$ sequência, apresenta-se a identificação das espécies nativas e estrangeiras encontradas.

\footnotetext{
${ }^{2}$ Uma prática comum nas oficinas litográficas conforme Davidson (1989), eram os chamados rótulos de estoque, os quais se caracterizavam por ser impressos sem o título, o qual poderia ser acrescentado posteriormente por impressão tipográfica. Esta modalidade de rótulo era interessante para os pequenos fabricantes que não podiam arcar com uma arte exclusiva, utilizando assim um rotulo presente em um livro de amostras e pedindo pequenas quantidades.
} 


\section{Identificação de espécies nativas e estrangeiras}

A partir da categorização dos animais, buscou-se averiguar a relação das espécies encontradas com a fauna brasileira. O que se percebeu é que nas produções existem referências tanto a animais nativos, como também a animais estrangeiros. As ocorrências foram divididas da seguinte forma:

1. Nativos - Aqueles que fazem parte da fauna brasileira. Quando os colonizadores chegaram, eles já estavam aqui. Muitos destes animais receberam o nome em tupi: aratanha, arara, piracanjuba, aracuã.

2. Introduzidos para criação - Aqueles que foram trazidos pelos colonizadores para fim de utilidade (consumo, transporte) e estão no Brasil até hoje na vida rural: galinha, galo, bode, cavalo, boi.

3. Introduzidos para uso doméstico - os cachorros e gatos trazidos para uso doméstico. Há relatos também de aves que foram trazidas, tais como o bico-de-lacre, e que se disseminaram pelas regiões brasileiras.

4. Totalmente exóticos em nosso meio - Por definição, animais exóticos são aqueles que não ocorrem naturalmente numa determinada região geográfica. Enquadrou-se aqui aqueles animais que não são vistos nem nas florestas brasileiras, nem nas criações. Quando presentes no Brasil, são animais de cativeiro, como os chimpanzés em zoológicos. Em meados do século XX, intui-se que o conhecimento destes animais pode ter advindo de livros, revistas, zoológicos, circo ou cinema.

5. Mitológicos - Pequeno grupo formado pelos dragões e a única fênix presente na coleção.

Dentre os grupos nomeados como "crustáceos, aves, rurais, insetos, répteis, peixes e mamíferos aquáticos, mamíferos domésticos, roedores, mamíferos selvagens, mitológicos e moluscos", o grupo aves foi aquele que apresentou maior incidência e diversidade de espécies, especialmente nas produções advindas da região Sudeste. Observa-se também que no caso de animais nativos, há exemplos em que o animal não habita o estado no qual o rótulo foi produzido, como o peixe "cavalo marinho" presente em um exemplar do estado de Minas Gerais. Contudo, tais ocorrências são exceções, sendo o mais comum ao se tratar de espécies nativas, possuir também relação com a fauna da região.

Percebe-se que a maior diversidade de espécies nos rótulos é brasileira. Agrupando os animais que fazem parte da mesma espécie, como machos, fêmeas e filhotes, a exemplo de cabra, bode e cabrito, identifica-se apenas 23 espécies estrangeiras diferentes, contra 92 espécies brasileiras (fig. 2). É possível que o número de espécies brasileiras seja ainda maior, visto que esta contagem se baseou especialmente na designação da aguardente ${ }^{3}$, salvo exceções, como o pássaro cardeal-do-nordeste, identificado apenas por meio da representação gráfica.

Figura 2: Caracterização da diversidade faunística dos rótulos. Fonte: Almeida (2018).

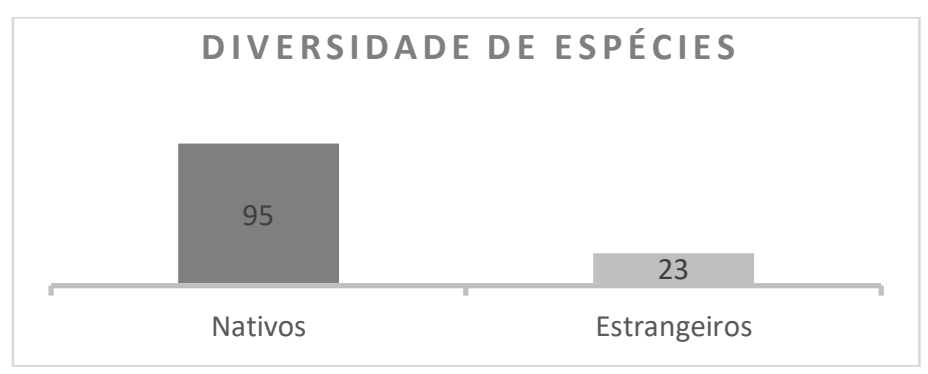

Ao contabilizar os rótulos cujos animais representados são espécies estrangeiras, obtém-se aproximadamente $38 \%$ dos 402 rótulos com figuras de animais. Já a soma dos rótulos que trazem animais nativos corresponde a $61 \%$ dos exemplares (fig. 3 ). Nota-se que os animais estrangeiros se repetem muito, mas sem grandes especificações em taxonomia ou na própria

3 Terminologia utilizada por Almeida (2018) para se referir ao título ou nome comercial da bebida. 
representação. Por exemplo, há muitos galos, mas não foram identificadas diferentes espécies de galo. Já no caso dos animais brasileiros, temos espécies com nomes mais específicos e que ocorrem apenas em um rótulo, sendo filhos únicos na coleção, notadamente no grupo das aves, que é, como já apontado, aquele que possui a maior diversidade de espécies. A seguir apresenta-se o comparativo entre as representações gráficas e os animais propriamente ditos.

Figura 3: Divisão das recorrências quanto à natureza dos animais. Fonte: Almeida (2018).

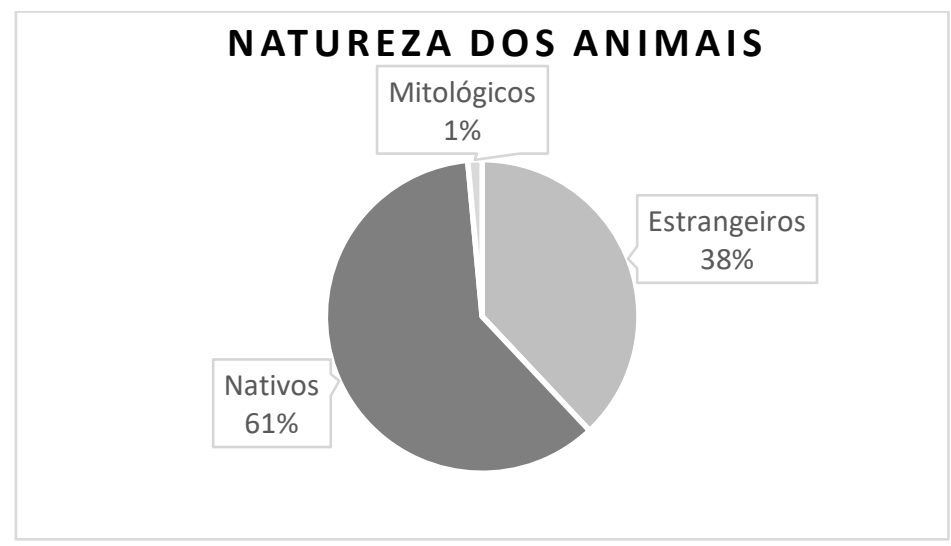

\section{Comparativo entre as representações gráficas e os animais}

Para embasar o comparativo sob a ótica do design da informação, utilizou-se parte do modelo de Aswhin (1979), que propõe a análise do estilo de ilustrações por meio de variáveis semânticas e sintáticas. O estilo das ilustrações seria determinado pela interação dessas variáveis, a presença e o relativo grau de cada uma. Este autor descreve sete variáveis e determina seus respectivos polos: consistência (homogenio/heterogenio), gama (contraído/expandido), enquadramento (disjuntivo/conjuntivo), posicionamento (simétrico/ casual), proximidade (perto/distante), cinética (estático/dinâmico) e naturalismo (naturalismo/não-naturalismo).

O objetivo deste artigo foi de trazer o comparativo entre o objeto real (animal) e sua representação (ilustração), para avaliação da semelhança entre o animal representado e sua espécie na natureza. Diante disto, as variáveis consideradas relevantes para esta análise foram as denominadas gama e naturalismo. A Gama avalia a ilustração de acordo com a sintaxe estabelecida por um ilustrador, que pode escolher entre explorar toda a gama de sua sintaxe ou se impor a limitações (Almeida, 2013). Ashwin (1979) exemplifica apontando que o ilustrador pode, por exemplo, ao trabalhar na cor, limitar a variedade de tons ou combinações de matiz. A amplitude dos efeitos utilizados é o que o autor denomina de gama. Os desenhos feitos no Cubismo analítico são um exemplo de estilo altamente contraído, com sua síntese da forma. Por outro lado, estilos mais naturalistas, com maior nível de detalhamento, exigiriam um gama com estilo mais expandido.

Nesta análise proposta, considerou-se a variável gama como o nível de detalhamento das ilustrações: contraído para as ilustrações dos rótulos com menos efeitos visuais, poucos tons e menor detalhamento no desenho, e expandido para aquelas ilustrações que utilizam mais recursos técnicos, efeitos visuais e detêm um maior detalhamento. Por exemplo, o rótulo Atum (fig. 4), tem uma representação do peixe bem sintetizada, chapado, sem nenhum detalhe da pele, das barbatanas ou mesmo volumetria; tais efeitos visuais poderiam ter sido explorados pelo desenhista gráfico, utilizando diferentes ferramentas e técnicas como pontilhismo e gradações tonais, por exemplo. Até a representação da água é simplificada neste exemplar, por tal razão, neste caso considerou-se o nível gama como contraído. Já o rótulo Águia (fig. 5), foi considerado com nível gama expandido, visto que a representação do animal conta com volumetria, luz e sombra, além do cuidado em detalhar as penas da ave com uso de hachuras. 
Almeida, S. S. T. \& Coutinho, S. | Entre a fauna e o design: um comparativo entre os animais e suas representações gráficas em rótulos de cachaça de meados do século XX

Figuras 4 e 5: Rótulos Atum e Águia (década de 1950). Fonte: Coleção Almirante, Acervo da Fundaj.
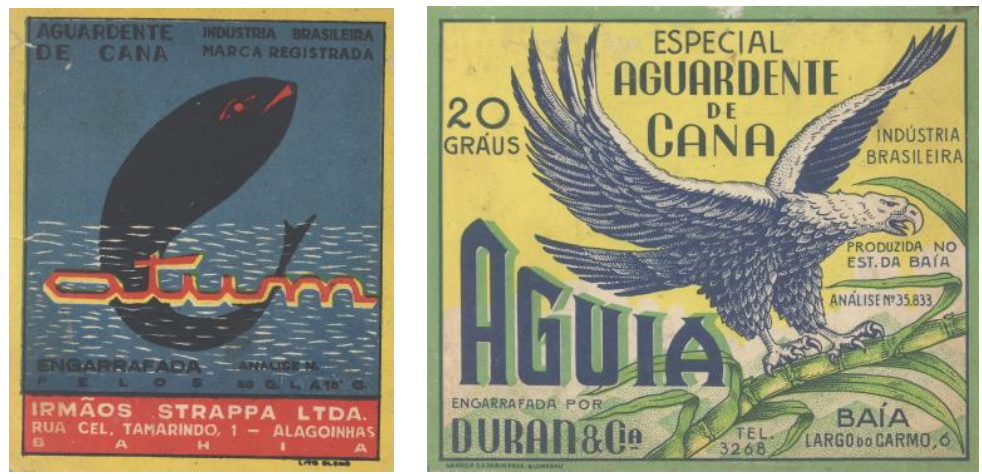

Contudo, dada a variedade de composições presentes nas produções, em termos de recursos gráficos utilizados, percebeu-se tal qual Aragão et. al. (2008), a necessidade de criar níveis intermediários na avaliação da variável gama. Assim adotou-se igualmente aos autores, mais três níveis, os quais foram designados neste estudo como: quase contraído, ambíguo e quase expandido (fig. 6). O rótulo Cisne Negro (fig. 6-a), por exemplo, foi considerado como quase contraído, visto que o cisne é pouco detalhado, tendo a representação das penas feitas apenas por linhas brancas simplificadas, sem explorar o uso de luz e sombra, volumetria ou mesmo mistura de cores. Todavia, esta produção possui um pouco mais de detalhes na ilustração comparativamente ao exemplar Atum (fig.4), além de possuir melhor execução técnica.

O rótulo Capivara (fig. 6-b), por sua vez, foi considerado como ambíguo (um pouco contraído e um pouco expandido). Neste exemplar temos uso de sombra e uma gradação de cores na representação do animal, no entanto, apesar destes recursos gráficos, a qualidade técnica não permitiu um melhor detalhamento, ficando desta forma entre as duas polaridades. Já no rótulo Biriba (fig. 6-c), temos o um bom detalhamento do cachorro com uso de gradação de cores, mas nota-se que o desenhista poderia ter se dedicado mais na caracterização do animal, desenhando pelos, por exemplo. Ou ainda, explorando mais o entorno, que se restringiu a um plano vermelho. Portanto, neste caso a produção teve a variável gama classificada com nível quase expandido.

Figura 6: Níveis intermediários entre as polaridades contraído e expandido da variável gama. Da esquerda para direita temos os rótulos (a) Capivara (década de 1940), (b) Cisne Negro (década de 1950) e (c) Biriba (década de 1950). Fonte: Coleção Almirante, Acervo da Fundação Joaquim Nabuco.

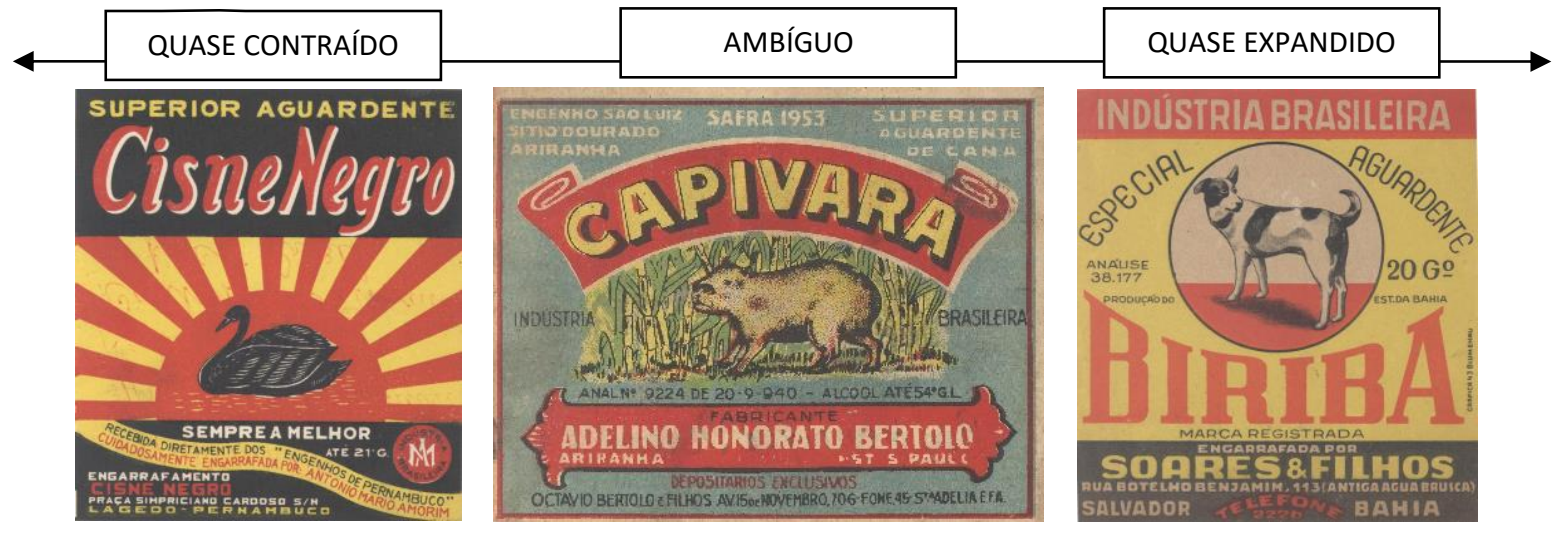

A segunda variável de Aswhin (1979), o naturalismo, serviu para avaliar o grau da plausibilidade dos eventos representados e sua correspondência ao mundo real. Fatores considerados foram: proporções, expressões do animal, semelhança com o animal real, posição em que se encontra e as ações nos quais estão envolvidos. Nos exemplares Touro (fig. 7) e Guache (fig. 8), o primeiro foi considerado não-naturalista, visto que o Touro está 
apoiando-se em letras, além do que, apresenta uma representação gráfica muito sintetizada do animal. Já o exemplar Guache foi considerado naturalista, pois a ave está apenas pousada em um filete de cana, sem nenhuma ação ou aspecto que discrepe fortemente da realidade, sua representação também guarda grande semelhança com a aparência deste pássaro (fig. 9).

Figuras 7, 8 e 9: (7) Rótulo Touro (década de 1950), (8) Rótulo Guache (década de 1940). Fonte: Coleção Almirante, Acervo da Fundaj. (9) Guaxe. Foto: Claudio Dias Timm (CC BY-NC-SA 2.0).
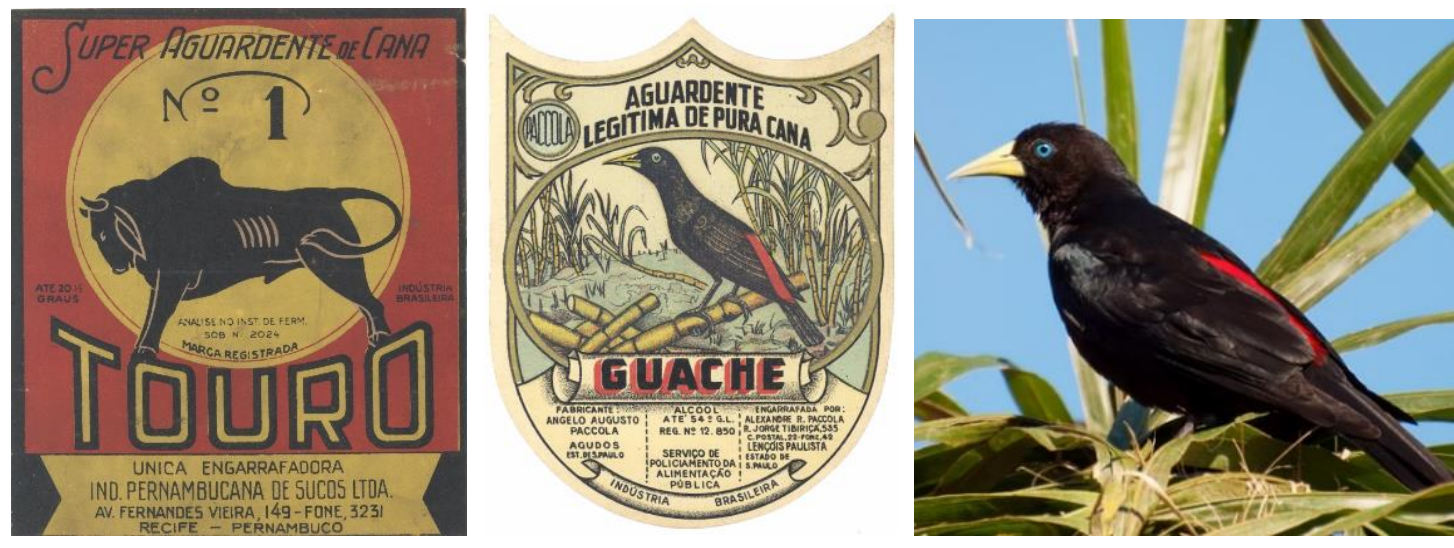

A partir da avaliação destes ingredientes na amostra de 402 rótulos com ilustrações de animais, percebeu-se que no quesito naturalismo, a maioria das representações de animais adotam o ingrediente naturalista (fig. 10). Nas marcas que adotam o não-naturalismo, normalmente o animal está envolvido em alguma ação relativa ao ato de beber, segurando uma garrafa ou taça, por exemplo. Ao relacionarmos tal variável com a classificação dos animais da Coleção, proposta por Almeida (2018), nota-se que representar graficamente os animais de modo naturalista era a pratica mais recorrente, salvo a categoria de animais mitológicos, que por se tratarem de seres imaginários, não há como enquadrá-los na outra polaridade; e a categoria crustáceos, por uma diferença de apenas 1 exemplar. As categorias nas quais o ingrediente naturalista se sobressai por uma grande diferença são as aves, os animais rurais, os mamíferos selvagens, os insetos, roedores e o grupo dos peixes (fig. 11).

Figuras 10 e 11: Ingrediente naturalismo avaliado nos 402 rótulos de animais e relação entre este ingrediente e a classificação proposta para as espécies representadas. Fonte: Almeida (2018).

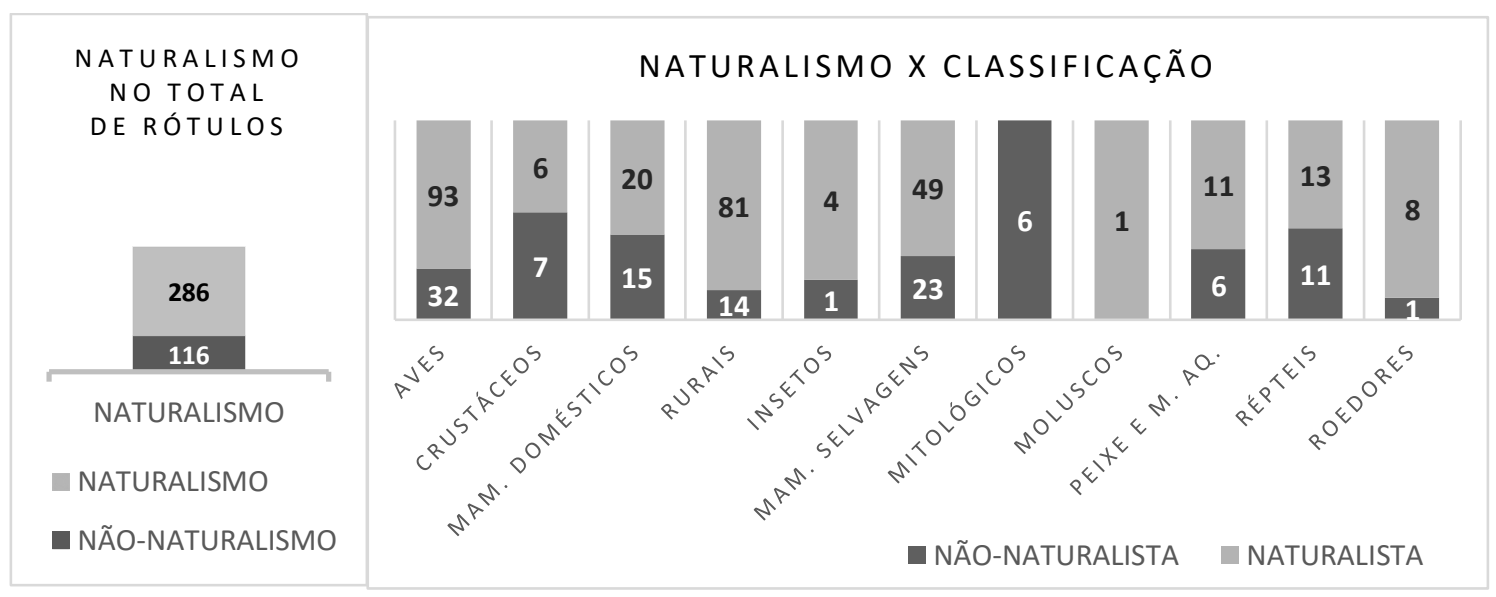

No caso do ingrediente "gama", que foi dividido em cinco níveis, aquele que se mostrou mais recorrente foi o nível "ambíguo", com cerca de um terço das recorrências, os níveis que tendem a um detalhamento expandido e aqueles que tendem a um detalhamento contraído ( ou restrito) dividem um número semelhante de ocorrências (fig. 12). Esta variável tem relação direta com o nível técnico da produção, e por tal razão muitas produções caíram na ambiguidade do detalhamento, visto que, se por um lado tentavam detalhar o animal tendendo à polaridade de gama expandido, por outro, perdiam detalhes por não possuírem um bom 
refinamento técnico, ocasionando erros no registro das matrizes, por exemplo. Por outro lado, cabe ressaltar que nem sempre os rótulos que foram enquadrados como "contraídos" ou "quase contraídos" detém menos qualidade técnica, visto que estas representações menos detalhadas compunham parte também do estilo destes artefatos.

Figura 12: Avaliação do ingrediente gama no grupo de rótulos de animais. Fonte: Almeida (2018).

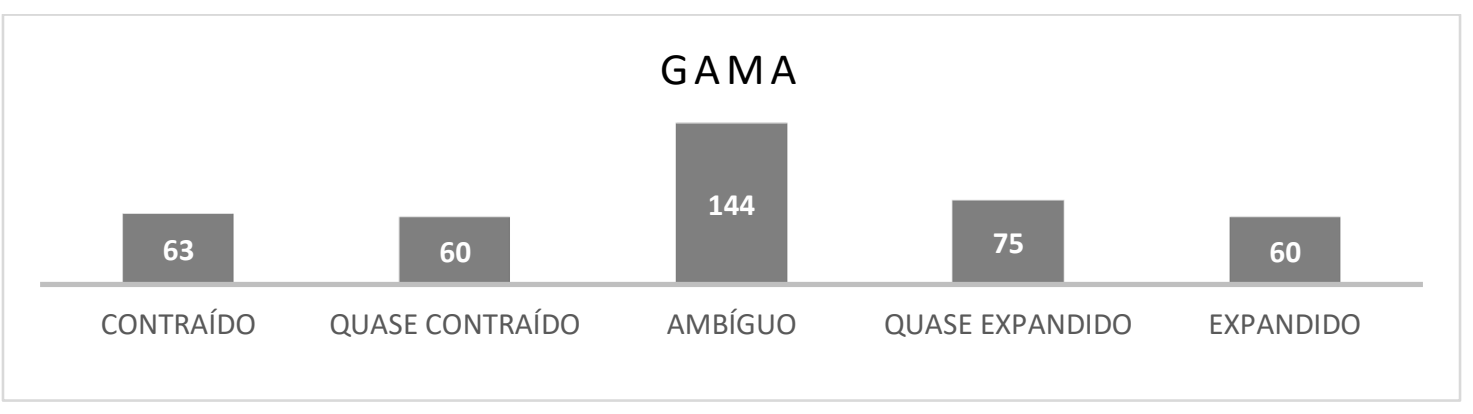

Foram observadas representações sintetizadas de animais que parecem de caráter intencional, como é o caso do rótulo Cumbe (fig. 13). Neste rótulo, apresenta-se a figura de um gato com gama bem contraída, sendo quase uma silhueta. Contudo, nota-se que existe conhecimento técnico pelos recursos utilizados na composição. O rótulo é impresso em preto, cinza e prata e o casamento das matrizes é bem executado, garantido o detalhe das partes em branco no animal. O recurso de pontilhamento que poderia ter sido aproveitado para detalhar o animal, foi empregado na fumaça da usina, comprovando que sua ausência não foi por desconhecimento, mas de caráter intencional. Compreende-se pela análise, que o naturalismo e a gama são variáveis que podem estar relacionados entre si, visto que, o baixo nível de detalhamento neste caso, comprometeu o naturalismo da representação.

Figura 13: Recortes do rótulo Cumbe e detalhes. Fonte: Almeida (2018).

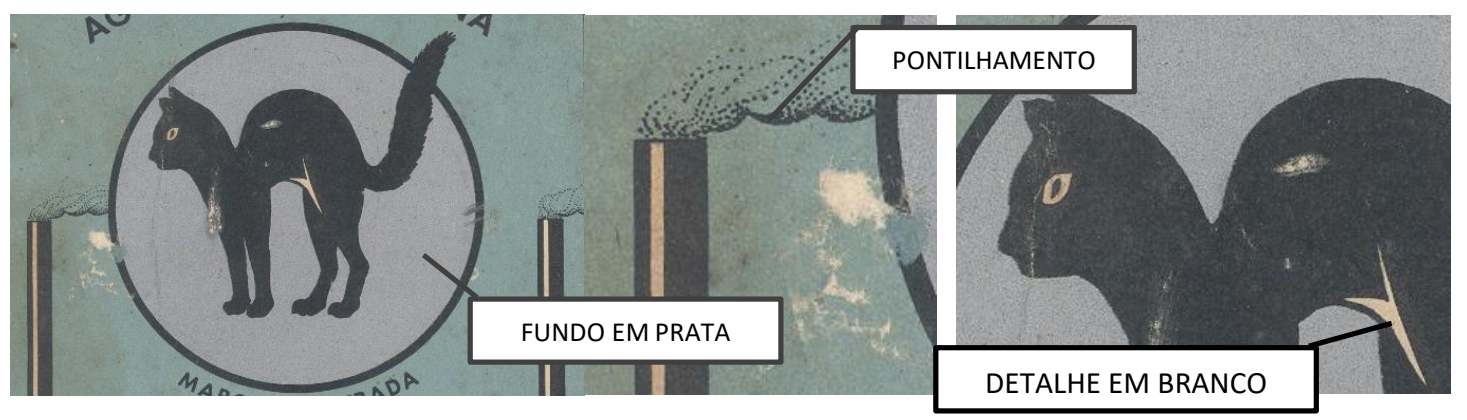

Pode-se dizer que de modo geral, quanto mais específico é o animal representado, maior é o cuidado dado a representação de suas características morfológicas, tendendo ao naturalismo e a gama expandida. De acordo com Almeida (2018), era comum que os rótulos de animais trouxessem como designação da aguardente, o nome do animal. Desta forma, a bebida podia ser identificada tanto pela leitura de seu letreiro quanto pelo reconhecimento do animal por meio de sua representação gráfica. Permitir que o reconhecimento se desse tanto em nível verbal como pictórico, contemplava também o público consumidor que não era alfabetizado.

Trazer espécies mais particulares era mais comum ao se tratar de referências de animais nativos. Como exemplo, observa-se o caso do caranguejo e do siri. Caranguejo é o nome utilizado genericamente para designar o tipo de crustáceo com cinco pares de patas e carapaça que vive predominantemente em áreas de estuário (manguezais). No entanto, de acordo com Ihering (1940), em sua época, era comum no Nordeste utilizar o termo caranguejo para se referir à espécie Uça Cordata, que é o conhecido caranguejo alaranjado (fig. 14). O Siri (fig. 15), por sua vez, se diferencia do caranguejo por ter patas nadadoras, além de ter uma carapaça maior e ser predominantemente marinho. 
Almeida, S. S. T. \& Coutinho, S. | Entre a fauna e o design: um comparativo entre os animais e suas representações gráficas em rótulos de cachaça de meados do século XX

Figuras 14 e 15: Na sequência, caranguejo uça e siri-azul. Fonte: https://caminhosdabio.wordpress.com/ tag/ comodiferenciar-caranguejos-uca-grauca-marinheiro-aratu-siri/.

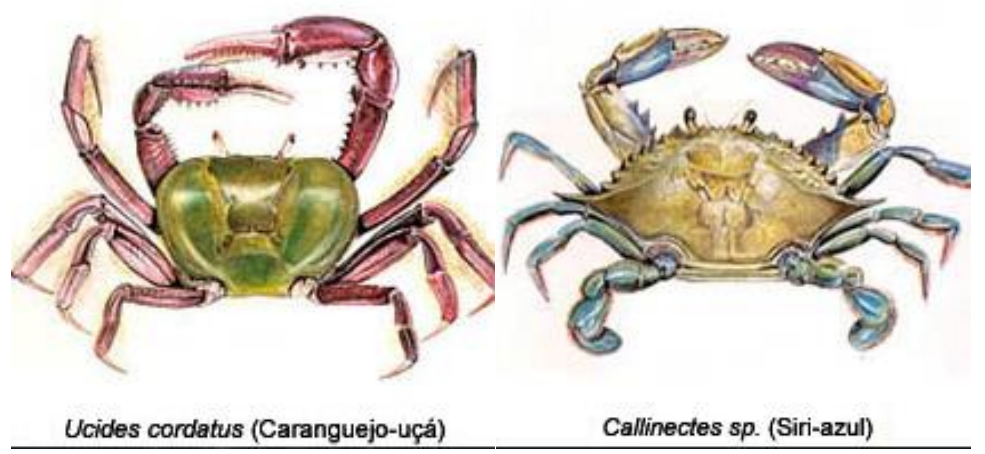

Observa-se o cuidado na representação das características principais como carapaça e patas, necessárias ao reconhecimento e diferenciação entre estas duas espécies nos rótulos. No rótulo da Aguardente Caranguejo (fig. 16), a representação traz a forma mais popular deste animal, aquele com a carapaça mais arredondada. No rótulo da Aguardente Siri (fig. 17), por sua vez, percebe-se que a escala do animal no impresso propiciou que o desenhista explorasse melhor suas características; o formato da carapaça é mais triangular e as patas traseiras, que são as nadadoras, receberam um cuidado especial, seguindo com propriedade sua referência faunística. O vermelho escolhido para os crustáceos difere da cor original de cada uma das espécies, no entanto, coincide com a cor dos mesmos quando esses animais estão preparados para o consumo culinário.

Figura 16: Rótulo da aguardente Caranguejo (PB) e recorte (década de 1960). Fonte: Coleção Almirante. Acervo da Fundaj.

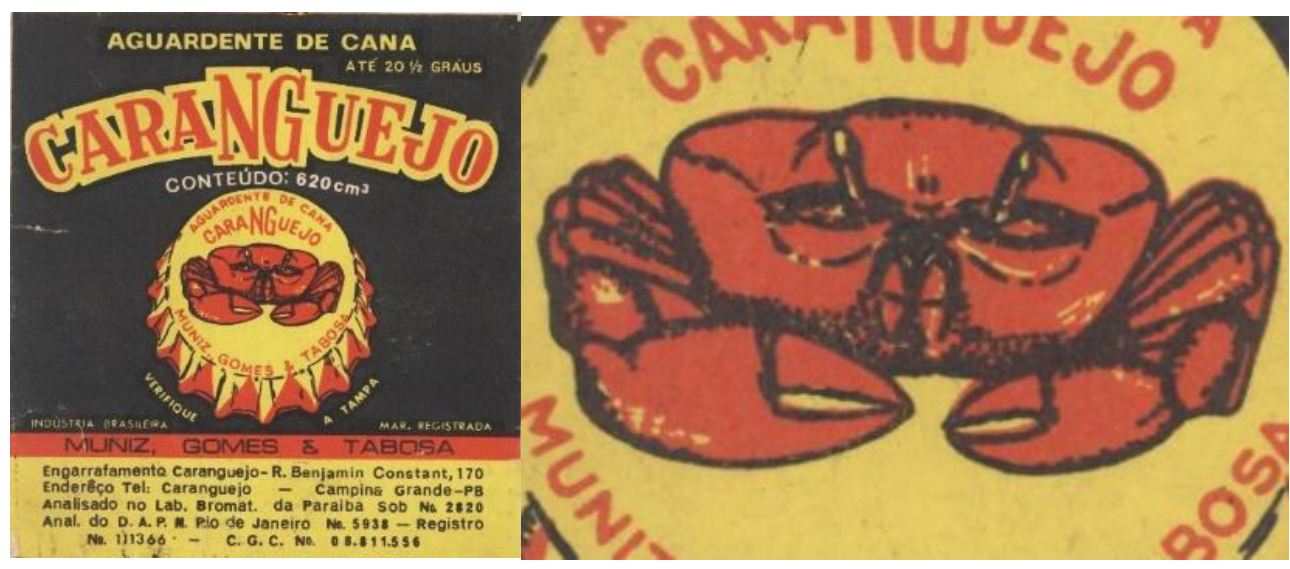


Figura 17: Rótulo da Aguardente Sirí (PE) (década de 1950). Fonte: Coleção Almirante. Acervo da Fundaj.

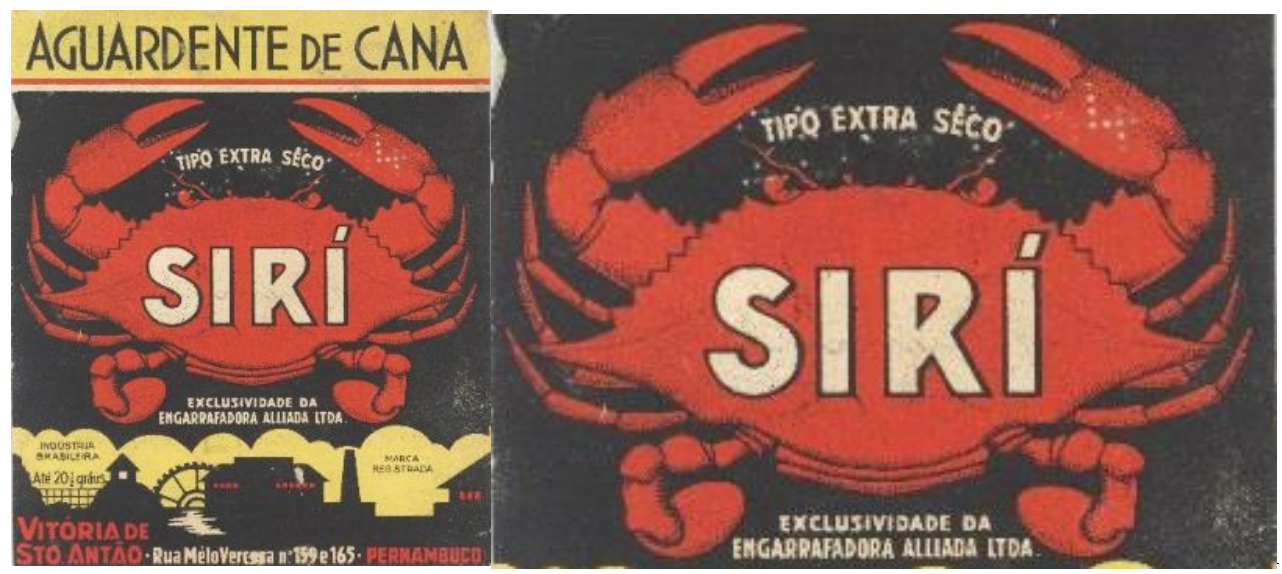

Enquanto nota-se maior caracterização nas espécies nativas, cujas referências eram conhecidas com mais propriedade pelos desenhistas da época, os animais de origem estrangeira costumam ser representados de forma mais genérica, tanto na designação da aguardente como na representação gráfica. O leão (fig. 18), por exemplo, conhecido das savanas da África, sendo comumente encontrado em zoológicos brasileiros, conta com dezessete exemplares na coleção. Contudo, apesar de possuir diferentes subespécies, é representado nas produções sem grandes especificidades, na ilustração ou na designação da aguardente (fig. 19). No exemplo do rótulo Leão, do estado do Piauí, há sim um cuidado nas gradações tonais, na caracterização naturalista do animal, mas não é possível identificar a subespécie representada em termos morfológicos. Tal fato reforça para esta análise que o conhecimento das espécies pelos desenhistas e pelo público, era determinante nas escolhas das formas de representação gráfica.

Figuras 18 e 19: Leão (CC0 domínio público) e Rótulo Leão (PI) (década de 1940). Fonte: Coleção Almirante. Acervo da Fundaj.
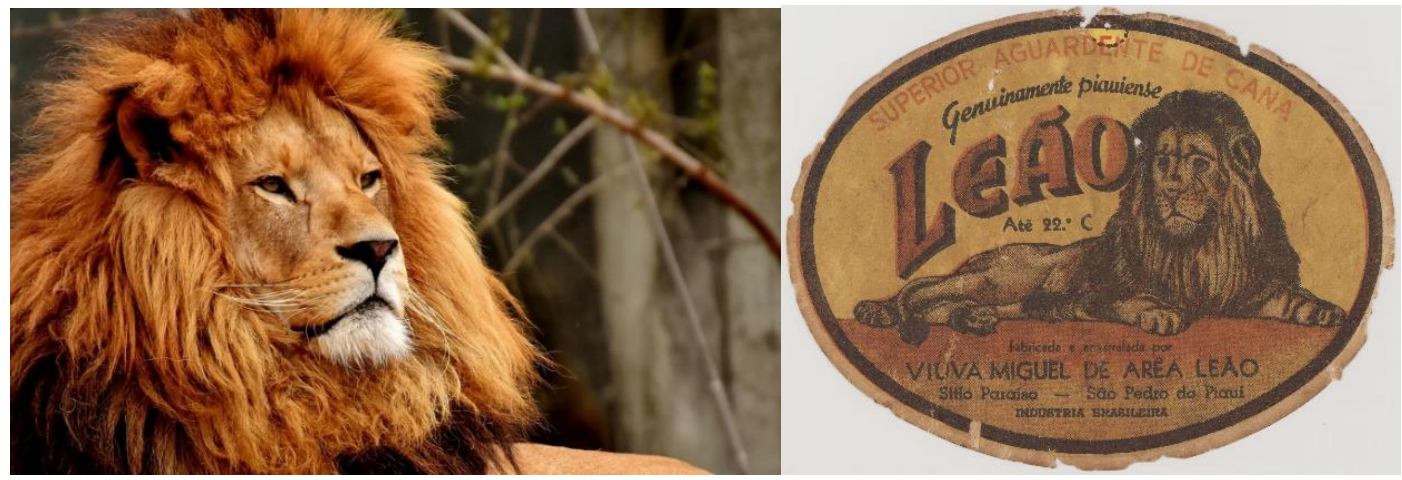

\section{Conclusões}

A partir das análises observa-se que, quando o animal era escolhido como temática principal na rotulagem da aguardente, havia uma predileção pela representação de espécies nativas, um repertório mais específico do público brasileiro. No período dos artefatos, entre meados do século $\mathrm{XX}$, o reconhecimento de animais específicos era algo mais comum graças a maior integração entre o campo e a cidade. Desta forma, o que mais se destaca neste estudo faunístico é a qualidade das representações das espécies nativas do ponto de vista das caracterizações morfológicas das espécies.

Comparando as representações com os animais presentes na natureza, observa-se que no quesito naturalismo, $71 \%$ das produções adota o ingrediente naturalista. No caso do ingrediente "gama", as ilustrações se mostraram com tendência ao detalhamento expandido. 
Estes são indicativos de que os desenhistas representavam mais detalhadamente os animais que faziam parte do cotidiano, visto que eram conhecedores das características necessárias para representá-los com maior naturalismo e nível de detalhes. Percebeu-se ainda a relação entre o nível de caracterização da representação gráfica e a importância do reconhecimento do animal, por parte do público não-leitor, garantindo assim o acesso à informação fundamental do rótulo: o nome do produto.

\section{Agradecimento}

Agradecimento especial à Fundação Joaquim Nabuco por ceder as imagens de rótulos da Coleção Almirante para este estudo.

\section{Referências}

Almeida, S. (2018). Bichos Boêmios: um estudo sobre recorrências, referências e análise de significado dos animais nos rótulos de aguardente da Coleção Almirante. Tese (Doutorado). Recife: Universidade Federal de Pernambuco.

Aragão, I.; Barreto Campello, S.; Ramos, H.; \& Hennes, M. (2008). Catalogação e análise dos rótulos de aguardente do Laboratório Oficina Guaianases de Gravura. Anais do $8^{\circ}$ Congresso Brasileiro de Pesquisa e Desenvolvimento em design. São Paulo, v.1 p. 318- 333.

Ashwin, C. (1979). The ingredients of style in contemporary ilustration: a case study. Information Design Journal, p. 51-67.

Davidson, J. (1989). The art of the cigar label. New Jersey: The Wellfleet Press.

Humbert, C. (1972). Label Design. Fribourg: Office du livre. Ihering, R. V. (1940). Dicionário dos animais do Brasil. (2. ed.). São Paulo:

Universidade de Brasília.

Lopes, S. (2004). Bio: volume único. São Paulo: Saraiva.

Melo, C. H. \& Ramos, E. (2011) Linha do tempo do design gráfico no Brasil. São Paulo: Cosac Naify.

\section{Sobre as autoras}

Swanne Almeida, Doutora, IFPE, Brazil <swanne.almeida@olinda.ifpe.edu.br>

Solange Galvão Coutinho, PhD, UFPE, Brazil <sol2015ufpe@gmail.com> 